\title{
Ritos Genéticos: uma abordagem discursiva do texto literário e suas contribuições para a Teoria da Análise do Discurso
}

\author{
GENETIC RITES: A DISCURSIVE APPROACH TO LITERARY TEXT AND ITS \\ COntributions to the Theory of Discourse Analysis
}

\author{
Denise B. A. Aguiar* \\ Décio Rocha**
}

Resumo: Este artigo busca atingir um duplo objetivo: por um lado, avaliar a produtividade do conceito de ritos genéticos (MAINGUENEAU, 2008) na análise de textos literários; por outro, explicitar as contribuições da análise dos textos literários para uma ressignificação do próprio quadro teórico da Análise do Discurso. Esse duplo trajeto será atualizado no contexto da semântica global proposta por Maingueneau (2008). No desenvolvimento da reflexão, o conceito de ritos genéticos é confrontado com diversas produções literárias, de diferentes períodos de nossa história cultural, tanto para apreendê-lo na especificidade da produção de sentido da escrita artística, quanto para levantar algumas de suas formas de inserção no próprio universo da construção ficcional, dentro de um movimento metalinguístico comum na literatura. Dentre os resultados alcançados, ganham destaque a pertinência da análise dos ritos genéticos para a consolidação da noção de prática discursiva e o lugar central ocupado pelo texto literário na produção de uma memória que institui formas de enunciabilidade implicadas com a própria constituição da língua.

Palavras-chave: Ritos genéticos. Texto literário. Semântica global.

\footnotetext{
* Doutorado em Literatura Comparada pela Universidade Federal Fluminense (2006). Professor Adjunto da UFF. Contato: denisebrasilaa@yahoo.com.br.

** Pós-doutoral na Universidade Federal Fluminense. Professor Associado da Universidade do Estado do Rio de Janeiro. Contato: rochadm@uol.com.br.
} 
Abstract: In this paper a double objective is pursued: on the one hand, to evaluate the productivity of the concept of genetic rites (MAINGUENEAU, 2008) in the analysis of literary texts; on the other hand, to explicit the contributions of the analysis of literary texts to a redefinition of the very theoretical framework of discourse analysis. This dual path will be followed in the context of global semantics proposed by Maingueneau (2008).In the development of our reflections, the concept of genetic rites is brought forward in various literary productions of different periods of our cultural history, so that we will be able to apprehend it in the specificity of production of sense in artistic writing, and also to survey some of its modes of insertion in the universe of fictional construction, within a metalinguistic movement typical of literature. Among the achieved results we highlight the relevance of the analysis of genetic rites for the consolidation of the concept of discursive practice and the centrality of literary text in producing a memory establishing forms of enunciability involved with the very constitution of language.

Keywords: Genetic rites. Literary text. Global semantics.

\section{Introdução}

Na apresentação da edição brasileira de Gênese dos Discursos, obra de Dominique Maingueneau, cuja primeira edição em língua francesa data de 1984, Sírio Possenti indica que os estudos na área de literatura têm recorrido com parcimônia ao quadro teórico de base discursiva proposto pelo linguista francês. Isso talvez se deva à resistência de uma tradição hegemônica de tais estudos no país, que aponta em outra direção e se difunde por todo um campo ocidental de teoria e crítica literárias. Em texto de 2010, o próprio Maingueneau comenta essa resistência, situando-a no contexto de uma herança romântica ${ }^{1}$ e estendendo-se ainda para um questionamento de mão dupla: é

1 "Isso se deve, sem dúvida, em parte às pressuposições herdadas da estética romântica, que opunha literatura ao resto das outras produções discursivas de uma sociedade. Haveria, por um lado, os enunciados 'transitivos', que teriam finalidade fora deles mesmos e, por outro lado, as obras verdadeiras, 'intransitivas', 'autotélicas', as da literatura, que teriam suas finalidades em si mesmas” (MAINGUENEAU, 2010). 
preciso se interrogar sobre quais pressupostos, conceitos e métodos da Análise do Discurso alteram a nossa apreensão da literatura, mas, por outro lado, é necessário também interrogar-se acerca da emergência de uma análise do discurso literário e suas repercussões sobre a própria teoria da Análise do Discurso.

É a partir dessa dupla interrogação de Maingueneau que buscamos situar o presente trabalho, com o objetivo de estabelecer possíveis diálogos de conceitos e pressupostos do autor com a literatura, confrontando-os com períodos, autores e obras, para avaliar sua produtividade. Nesse contexto, acordamos atenção particular ao conceito de ritos genéticos (MAINGUENEAU, 2008), o qual contribuirá para que se repense o encontro entre tex to e contexto, uma vez que estará referido ao modo de articulação entre, por um lado, a história pessoal do autor em coordenadas (empíricas) de espaço e tempo específicas e, por outro, as coordenadas (discursivas) espaçotemporais, que dizem respeito ao universo instituído pelo autor.

\section{Questões a Propósito dos Ritos Genéticos}

Em Gênese dos discursos, Dominique Maingueneau trabalha com o conceito de ritos genéticos, na tentativa de delinear elementos importantes na constituição de uma semântica global, elemento-chave para a discussão do discurso na obra do autor. $\mathrm{Na}$ exposição de tais ritos como um "conjunto de atos realizados por um sujeito em vista de produzir um enunciado" (MAINGUENEAU, 2008, p. 132), Maingueneau adverte para o fato de ser esta uma noção mais ampla que a de "pré-texto", porque inclui procedimentos não escriturísticos (viagens, meditações etc.), que, vistos geralmente como elementos ligados à maneira pessoal como um indivíduo lida com sua escrita, nem por isso deixam de estar relacionados a um plano de restrições discursivas.

Ao afirmar a não existência de incompatibilidade entre os ritos pessoais e os ritos determinados por um pertencimento institucional e discursivo, Maingueneau evoca exemplos como o de Zola, cuja tarefa individual de pesquisas de campo e registros de feição "científica" contribui para definir o estatuto do escritor naturalista. Além dos casos evocados no mesmo texto, inúmeros outros comparecem a um exercício de interlocução, ainda que 
breve, entre esse pressuposto e a história da literatura. De fato, a configuração de ritos genéticos simultaneamente pessoais e coletivos pode ser atestada, seja em maior ou menor grau de evidência, em muitos momentos fundadores da própria memória dos estilos literários, como nos acenam alguns exemplos expostos a seguir.

No século XVIII, no Brasil, é conhecida a ligação entre os poetas árcades e o movimento mineiro da Inconfidência. Momento de explícita aliança entre as faces artística e política dos intelectuais de Vila Rica, o episódio ganhou notoriedade histórica como forma, ainda que estreita, de resistência colonial e se constitui como um interessante exemplo do sistema de restrições e pertencimento discursivo que atravessa também o literário. No limiar da fundação de uma modernidade advinda da Ilustração, a atividade dos poetas mineiros em permanente diálogo com as academias - tivessem elas funcionamento real ou não ${ }^{2}$ - é permeada por ritos genéticos que ultrapassam a perspectiva da criação estritamente individual, desde a própria fundação da Arcádia Ultramarina até a adoção de pseudônimos pastoris, que dão visibilidade à proposta de imitação dos clássicos. De alguma maneira, a figuração da subjetividade sob a máscara dos pastores, no universo da escrita literária, também se correlaciona ao exercício de uma outra face, pública, que vinha se consolidando e se ligava ao desejo de mudanças inspiradas nas Luzes refletidas da Europa. O fenômeno que Alfredo Bosi caracteriza como "o florescimento de gêneros nascidos da aberta inserção na vida pública: sermão, artigo, discurso" (BOSI, 1985, p. 92) contribui ainda para atestar um tipo de escrita que atrelava a criação individual a formas mais públicas de criar e agir. São gêneros orientados para a intervenção pública, que se encontra, nessa medida, com as representações ilustradas e neoclássicas partilhadas seja pelo estatuto poético e classicizante das máscaras pastoris (Fido, Glauceste, Dirceu), seja pelo viés abertamente político das Cartas Chilenas. Antonio Candido nota que, no período em questão, "houve entrosamento acentuado

${ }^{2}$ Segundo Massaud Moisés, a famosa Arcádia Ultramarina, marco da literatura árcade no Brasil, nem chegou a se reunir propriamente, "por motivos ignorados" (2004, p. 35). Consideramos, entretanto, que isso não dilui a força simbólica e o sentido associativo que as arcádias imprimiram ao movimento artístico da época, em diversos lugares. 
entre a vida intelectual e as preocupações político-sociais" (CANDIDO, 1980, p. 96). O que harmoniza esses dois planos, o que permite compreender de que maneira ambos partilham um mesmo sentido global, é a "confiança na força da razão, considerada tanto como instrumento de ordenação do mundo, quanto como modelo de uma certa arte clássica, abstrata e universal" (CANDIDO, 1980, p. 96).

Em Portugal, a Questão Coimbrã, que marca a substituição da tradição romântica pela escola realista, produz outra ocorrência interessante de ritos genéticos: a violência do confronto verbal que os jovens realistas estabeleceram com os antigos românticos - alinhando-se ao sentido maior de luta contra as opressões sociais que o século XIX fazia despertar - chegou à concretude do duelo. Como se sabe, em 1866, por conta de uma polêmica literária, Antero de Quental e Ramalho Ortigão realizaram, na cidade do Porto, um "duelo a espada", em uma representação algo pitoresca do espírito de combate que inegavelmente caracterizou a escrita realista, em sua investida contra tradições, estruturas sociais, religiosas, morais etc. Não se trata propriamente de um ato diretamente ligado à criação desta ou daquela obra, mas integra um conjunto de posturas que os realistas portugueses associaram ao seu processo de escrita. As atitudes desafiadoras da ordem estabelecida (seja ela política, moral/religiosa ou social), sob o signo do combate, da luta movida pelo sonho, tanto instituem um modo de ser baseado no enfrentamento, com o qual aqueles homens projetam novas organizações da experiência social e política, quanto acompanham o tom das práticas linguageiras - como podemos verificar na poética de Cesário Verde ou do próprio Antero de Quental $^{3}$ e, ainda, na temática anticlerical de textos de

${ }^{3}$ Difícil não evocar aqui um conhecido soneto de Antero de Quental, que atesta a decadência dos paradigmas românticos e tradicionais em proveito de uma nova ordem e uma nova poética, sob o signo do combate e da luta: "Tu, que dormes, espírito sereno,/Posto à sombra dos cedros seculares,/Como um levita à sombra dos altares,/Longe da luta e do fragor terreno,/Acorda! É tempo! O sol, já alto e pleno,/Afugentou as larvas tumulares.../Para surgir do seio desses mares,/Um mundo novo espera só um aceno.../Escuta! É a grande voz das multidões,/São teus irmãos, que se erguem! São canções.../Mas de guerra... e são vozes de rebate!/ Ergue-te, pois, soldado do Futuro/E dos raios de luz do sonho puro,/Sonhador, faze espada de combate!" (Odes modernas, 1865.) 
Eça de Queirós, bastante desconstrutora para a sociedade portuguesa do século XIX.

Talvez um caso mais complexo e interessante para analisar, no que diz respeito às relações entre uma obra e seus ritos genéticos, seja o de José de Alencar na escrita de As Minas de Prata. O Romantismo constitui os contornos de sua escrita e de seus escritores no espaço de entrecruzamento entre o indivíduo solitário, importante matriz de uma subjetividade ascendente no período, e o indivíduo cidadão, partícipe das comunidades nacionais, organizadas em um novo contrato social, a partir das revoluções burguesas. No encontro entre um eu íntimo e um eu social, o artista romântico se coloca a tarefa de ajudar a construir um imaginário nacional, que não pré-existia a ele. Buscando fontes históricas, especialmente em arquivos como o do Instituto Histórico e Geográfico Brasileiro (IHGB), e se configurando publicamente como um artista pesquisador de tais fontes, o escritor projeta sobre seu romance também certa aura de preservação ou revelação do passado nacional. Freitas (2009), pesquisando a escrita da história nos primeiros capítulos do romance, escritos em 1862, identifica que os documentos e relatos do Brasil Colonial colhidos por Alencar no IHGB são legitimados por ele, que, de acordo com seu projeto romanesco, seleciona e hierarquiza fontes, dialogando com a própria historiografia do período. Em outras palavras, o romance, que parte de uma pesquisa sobre o nosso século XVII, rito fundamental para abonar uma dada imagem das origens da sociedade brasileira, participa, também ele, da escrita da história dos oitocentos no Brasil, ou seja, do olhar que um momento já dominado pelo ideário nacional "independente" lança sobre o passado colonial. Trata-se, portanto, de um rito genético da escrita literária que, articulado com um projeto de construção de uma memória histórica, acaba por ajudar a escrevê-la, ao mesmo tempo que legitima a si mesmo. Essa situação corresponde ao conceito de enlaçamento, proposto por Maingueneau (2010), segundo o qual a enunciação pressupõe a existência de um mundo que, no final das contas, se consolida por meio desse mesmo ato de enunciação, ou seja, o que o texto diz já pressupõe uma cena de fala que o torna possível naquele momento, naquela dada sociedade, e é justamente esta mesma cena que, ao validar o discurso que nela se inscreve, se confirma como válida. Assim, se a obra de Alencar se inscreve na cenografia de recuperação de 
uma origem nacional - da qual participam outros gêneros de textos, enunciadores e coenunciadores -, é fato também que ela contribui para a legitimação dessa busca, empreendida no século XIX.

Muitos outros casos poderiam ser acrescidos aos que aqui expusemos, configurando práticas de escrita literária integrantes dessa ou daquela vocação enunciativa, desenvolvidas nos marcos de sistemas de restrições semânticas possíveis de identificar na história da literatura - que também é parte da história das sociedades. Tomadas em seu conjunto, elas confirmam a ideia de que

... a vocação enunciativa supõe uma harmonização mais ou menos estrita entre as práticas individuais do autor e as representações nas quais ele se reconhece e que comunidades mais ou menos amplas verão, por sua vez, encarnadas por ele. (MAINGUENEAU, 2008, p. 133).

Ao lado dos ritos genéticos, a enunciação se articula, também, com a maneira como os textos circulam, são recebidos e consumidos. E tais condições não se podem reduzir a fatores totalmente externos, isentos de qualquer relação com a criação do texto literário, elementos não marcados de um fenômeno social sem historicidade, sem ligação com os modos de produção dos próprios textos, assim como com os demais integrantes de uma semântica global.

Um breve exercício de análise da nossa literatura - suas condições de produção e circulação - comprova a interdependência entre o que Maingueneau caracteriza como "um 'acima”" e um "abaixo' da enunciação" (MAINGUENEAU, 2008, p. 134). Afinal, a cena de leitura solitária de um livro, na intimidade da casa burguesa, como nos demonstra Chartier (2009, p. 92), é indissociável do novo pacto de subjetividade que a modernidade do século XVIII produziu, tanto quanto a afirmação da obra como uma mercadoria a ser consumida também individualmente ou, pelo menos, em círculos familiares, no mesmo espaço da esfera privada. Esta é, por exemplo, a cena descrita por Alencar, jovem ledor de sua família no século XIX no Brasil, tal como rememorado pelo autor em Como e por que sou romancista ${ }^{4}$.

${ }^{4}$ Disponível em: <http://migre.me/sleh4>. 
O mesmo tipo de harmonização entre ritos genéticos, textos e modos de divulgação, se pode observar nos primeiros escritos modernistas, orientados para o escândalo, para um sentido de ruptura, e apresentados na Semana de Arte Moderna, de tônica igualmente escandalosa e rupturista. As profundas inovações formais, o sentido revolucionário da arte modernista naquele início da década de 20 , perderiam parte de sua força sem a agitação da Semana, sem a investida sistemática, deliberada e avassaladora contra uma tradição artística e social que perdurava no Brasil.

Mais recente e em contexto totalmente distinto, o caso de parte da literatura das décadas de 70/80 do último século no Brasil também pode ser associado à mesma caracterização feita por Maingueneau. Tributários de um pacto neorrealista ou mesmo naturalista, o memorialismo político e o romance-reportagem das décadas de 70/80 no Brasil assumiam claramente a tarefa de restituição da informação interditada, censurada, no país. Memórias dos porões da ditadura e narrativas que reconstituíam crimes ${ }^{5}$ buscavam revelar aquilo que não era acessível ao cidadão comum, hipnotizado pela programação tão encantadora quanto censurada/manipulada das telinhas de TV. Em uma produtiva diluição de fronteiras entre literatura e texto informativo, a divulgação e consumo dos livros, portanto, replicava o mesmo compromisso com a verdade factual, que as próprias obras, por meio de diversos recursos de linguagem, buscavam expressar na tessitura narrativa ${ }^{6}$. A sensação de descobrir os bastidores de algo que querem esconder do cidadão/leitor comum se encontra com o posto da autoridade enunciativa de quem revela esse algo que o cidadão quer saber.

Inscrita no mesmo contexto, a produção literária que ficou conhecida como "poesia marginal" moveu-se em terreno bastante distinto. Para não ceder à tentação de caracterizações monolíticas, que fazem parecer

${ }^{5}$ Nesta lista, entram tanto narrativas de Fernando Gabeira e Alfredo Sirkys quanto obras de cunho mais jornalístico, como Aracelli, meu amor, de José Louzeiro.

${ }^{6}$ Apenas para dar um exemplo, no livro de Gabeira, a exposição para o leitor do sequestro do embaixador americano - fato histórico de grande interesse para a época e central na construção do livro de memórias - se dá por meio da reprodução do telegrama que uma agência de notícias teria recebido com a manchete. Nada mais concreto, factual, "verdadeiro", para fundamentar um pacto de leitura no qual a condição de leitor embute a aceitação de ser guiado pelo autor-narrrador. 
homogêneas experiências sociais e culturais atravessadas pela diversidade, tomamos o exemplo da poesia englobada por tal denominação, seus ritos genéticos e a construção de sua semântica global. Em uma das obras críticas fundamentais sobre o período, Pereira (1981) disseca a especificidade desse fenômeno literário, que buscou dar um tipo peculiar de resposta às mesmas questões da dura época com que se deparava a "literatura-verdade" a que nos referimos anteriormente. Com um batismo que carrega, em princípio, o sentido do que está à margem do grande mercado editorial, o conjunto das produções abrigadas sob esse rótulo de "poesia marginal" acalentou uma efervescência de produção artística e pensamento crítico igualmente situado nas margens das falas consentidas durante a ditadura militar. Com circulação restrita a círculos relativamente pequenos de estudantes, escritores e intelectuais, as poesias eram produzidas por escritores agentes autônomos da íntegra do próprio processo de produção, reproduzidas em mimeógrafos ou offset e vendidas de forma alternativa, de mão em mão. Assim, os ritos genéticos da produção (em grupos pulverizados de poetas, a partir de um movimento de observação das temáticas miúdas do cotidiano, com uma postura de negação de possibilidades mais comerciais de escrita literária, etc.) se articulam com toda uma rede de circulação, na construção de sua semântica global, tal como se encontra indiciada, embora não nomeada dessa maneira, por Pereira, em sua minuciosa análise desse fenômeno literário:

... destaca-se o profundo entrelaçamento que se pode observar entre os diversos elementos que o constituem: p. ex., a estreita relação entre a temática dos textos, a linguagem através da qual esses temas são tratados e mesmo o modo de produção dos livros [...]. Parece-me difícil apreender a especificidade deste fenômeno da 'poesia marginal' sem considerar estes elementos apontados na totalidade de suas relações, is to é, na sua inter-relação. (PEREIRA, 1981, p. 347).

\section{Ritos Genéticos como Motes da Construção Ficcional}

Outra hipótese com que qualquer estudioso de literatura pode trabalhar - e certamente já há quem o faça - é a de que, na própria escrita literária, se encontram rastros desses ritos genéticos, dessas condições de circulação e 
consumo da obra, seja como traço indelével do processo de criação, seja oferecido ao público como um recurso de reafirmação de dada rede de sentidos. Em outras palavras: o exercício metalinguístico, autorreferencial, frequente na literatura, permite supor que esses elementos podem figurar como objetos de representação, componentes de um universo ficcional.

Um dos casos mais famosos da literatura brasileira, quando se fala desse tipo de representação, é o de São Bernardo, romance de Graciliano Ramos, em que o personagem Paulo Honório assume, no universo ficcional, a escrita do livro cuja narrativa será trazida ao leitor. Os ritos genéticos representados no livro de Paulo Honório - que é escrito dentro do romance de Graciliano - se revelam em uma caminhada que, partindo de relações marcadas pela onipresença do capital, chega à íntima e trágica autodescoberta do personagem, despertada pelo "pio da coruja". Tanto o projeto inicial de enunciação, formatado como linha de produção e com clara separação entre os produtores e o dono dos meios de produção, quanto a enunciação depois efetivada e suas práticas discursivas correspondentes são descritos em seus detalhes. Ao conjunto de práticas discursivas associáveis a cada um dos projetos do livro (o inicial e aquele que o personagem-narrador realiza) correspondem experiências sociais reconhecidas pelos leitores: seja pela identidade com os mecanismos de produção capitalista, sob a batuta do coronelismo nordestino, seja pela inflexão intimista que o chamado romance de 30 do Modernismo brasileiro abriu como possibilidade. Em São Bernardo, a segunda forma de enunciar, aquela que na verdade já faz parte do próprio romance, do mundo por ele representado, assume a tarefa crítica de corroer a primeira, pela exposição de uma existência violenta que se conjuga com recursos narrativos tão secos quanto a vida e a solidão do personagem ${ }^{7}$. A dolorosa tomada de consciência do Paulo Honório narrador de sua própria história, em meio a ritos ou práticas discursivas ligadas à reflexão, ao mergulho em si mesmo, põe em destaque que o afã de possuir, de acumular, foi algo que tragou indivíduos e relações interpessoais e, por fim, a ele mesmo em

${ }^{7}$ Cf. Cândido, no ensaio "Ficção e confissão": "Este grande livro é curto, direto, bruto. Poucos, como ele, serão tão honestos nos meios empregados e tão despidos de recursos; e esta força parece provir da unidade violenta que o autor lhe imprimiu" (p. $32)$. 
sua condição humana. Essa escrita, advinda da solidão e da meditação, não seria possível no modo de produzir o livro cogitado de início, marcado pela divisão de trabalho em moldes capitalistas. Elas se excluem mutuamente, já que uma prevê o silenciamento da rede de sentidos que a outra evoca.

Em outro momento de nossa história literária, Machado de Assis também opera a corrosão dos ritos genéticos legitimados pelas instituições vigentes. Em plena voga do cientificismo, que se espraiava por diversos setores da vida social e cultural em fins do século XIX, Machado deixou espalhadas por suas obras inúmeras pistas de seu significativo deslocamento em relação aos métodos pretensamente científicos e objetivos de descrever e escrever a realidade. $\mathrm{O}$ desejo de exatidão, as marcações da concretude da experiência, que se articulam com os ritos genéticos comentados por Maingueneau na referência a Zola, são alvo das desconstrutoras ambiguidades e ironias machadianas. Para além do famosíssimo caso de ambigüidade em Dom Casmurro, outros inúmeros sinais dessa desconstrução se espalham por sua vasta obra.

A abertura do conto $O$ caso da vara, por exemplo, traz um aberto desrespeito às normas da apreensão objetiva da realidade pela construção inusitada da referência de tempo: "Damião fugiu do seminário às onze horas da manhã de uma sexta-feira de agosto. Não sei bem o ano, foi antes de 1850.” (ASSIS, 1986a, p. 577). A lembrança do detalhe do dia da semana e até da hora contrasta estranhamente com a referência difusa ao ano, referência mais ampla, mais possível de ser lembrada ou evocada. Nada mais adequado a um texto que enfrenta os paradigmas de racionalidade de uma sociedade baseada na escravidão e no silenciamento, tema do conto que expõe a crueldade do castigo desigual entre o rapaz branco e rico e a menina negra. Em $O$ alienista, a corrosão do modelo racionalista e cientificista, que atravessava os ritos genéticos do modelo dominante de literatura nas sociedades europeias daquela época, atinge seu ponto máximo. As desventuras do Dr. Bacamarte e a inversão irônica do desfecho atestam o fracasso que o autor divisava no método da observação e descrição do real, tão caro à tradição realista de seu tempo.

Não podemos aqui, pelos limites do texto, discutir se Machado estaria ou não nos marcos da vocação enunciativa dos realistas - se ele rejeitava verdadeiramente sua inscrição nela ou se, percebendo suas limitações, buscava 
alargar as fronteiras do modo de apreensão de um real complexo, para além das aparências. De todo modo, podemos constatar um mal-estar em relação a ritos genéticos harmonizados com traços da literatura realista, que estão também indicados no exercício metalinguístico de Bentinho, quando ele explica o propósito da narrativa que apresenta ao leitor: "O meu fim evidente era atar as duas pontas da vida, e restaurar na velhice a adolescência. Pois, senhor, não consegui recompor o que foi nem o que fui. Em tudo, se o rosto é igual, a fisionomia é diferente." (ASSIS, 1986a, p. 810). A narrativa que se segue, em tudo precisa, detalhista, e ao mesmo tempo imprecisa, suspeita, põe em xeque um pacto de enunciação, subentendido no período realista, em que a autoridade do enunciador não poderia ser posta à prova pelos coenunciadores. Tal noção de coenunciação, aliás, ainda tão longínqua para a maioria dos escritores da época, é exposta ironicamente, em outra obra machadiana, pelo intolerante Brás Cubas:

O maior defeito deste livro és tu, leitor. Tu tens pressa de envelhecer, e o livro anda devagar; tu amas a narração direita e nutrida, o estilo regular e fluente, e este livro e o meu estilo são como os ébrios, guinam à direita e à esquerda, andam e param, resmungam, urram, gargalham, ameaçam o céu, escorregam e caem... (ASSIS, 1986a, p. 583).

Mas nem só de inversão e corrosão vivem as representações dos ritos genéticos no interior das próprias obras literárias. Muitas delas materializam esses ritos no rumo da confirmação das concepções de expressão artística dominantes em sua época. No romance Luciola, de José de Alencar, a escrita da narrativa - já uma representação ficcional, interna à obra, portanto harmoniza-se com a ideia da revelação da intimidade, do esmiuçamento de uma alma, sentimental e em tudo oposta à reificação do mundo, à transformação de tudo em mercadoria, forma de rebeldia inscrita na relação ambígua do Romantismo em geral com a sociedade burguesa. Se a escrita em forma de uma longa carta, com uma destinatária individual, já acena com uma rede de sentidos ligada ao privilégio da subjetividade sobre o mundo material, o final da narrativa, com a menção ao fato de o narrador ter "vazado toda a sua alma" para outro indivíduo, atesta essa concepção de arte que alimenta o artista romântico e se alimenta das posturas dele. 
A exemplo de várias outras práticas discursivas, enredadas a práticas sociais, esse processo de representação autorreferencial ou metalinguística na literatura, longe da mera imanência sedutora do artístico, inscreve-se em um processo histórico. Em O contexto da obra literária (1995), Maingueneau aponta que "é sobretudo a partir do século XIX que o escritor oferece como espetáculo seus ritos genéticos e a sociedade aprecia sonhar com eles” (1995, p. 49). Substitutos dos salões predominantes nos séculos XVII e XVIII, os cafés do século XIX se apresentam com espaços de exercício de uma boemia em tudo associada à própria escrita romântica e à configuração da "marginalidade" de seus artistas, a dissipar tempo e dinheiro, em sua inserção ambivalente no mundo burguês.

Com seu "estatuto duplo" - de realidade histórica e de sintoma das posições estéticas que embasam obras -, os ritos genéticos se transformam em espetáculo justamente quando a aura do indivíduo está em alta e quando a literatura é consumida não mais como produto universal do Belo, mas como expressão de uma subjetividade que se comunica, no circuito de leitura privada, com outra subjetividade. O modo de vida do escritor assume, assim, um lugar de interesse.

As imagens e projeções feitas sobre esse modo de vida, entretanto, não se baseiam necessariamente, ou meramente, em elementos biográficos. $\mathrm{Na}$ cadeia de significações que uma obra articula, as posições estéticas ajudam a corroborar dadas imagens de ritos genéticos. Apenas para ficar no exemplo do Romantismo, a figura de poeta como "cortejador do nada" (cf. GIVONE, 1999) advém tanto desse espetáculo público de que nos fala Maingueneau, quanto de indicações dispersas pelas obras. É o caso, sem dúvida, de Álvares de Azevedo: a figura que ele eternizou como poeta provavelmente tem muito menos ligação com a biografia de sua curta vida ${ }^{8}$ do que com as imagens que sua obra deixou inscritas no imaginário cultural. A personagem empobrecida e irônica do poeta presente em "Minha

${ }^{8}$ Lembremos aqui a polêmica biográfica apontada por Sílvio Romero, em sua História da Literatura Brasileira, de 1888. Em certa confusão entre vida e obra, formaram-se dois partidos: de um lado, os que o supunham um jovem estudioso e, em geral, recolhido em suas fantasias inocentes; de outro, os que o identificavam como depravado, ameaça à moral da época. 
desgraça" não se relaciona tanto com a vida do autor (filho de família ilustre e abastada ${ }^{9}$ ), mas com a nova forma de inserção do artista e da arte no mundo da mercadoria. Da mesma maneira, pouco se sabe verdadeiramente acerca dos problemas de saúde que o levaram à morte, mas o verso "foi poeta - sonhou - e amou na vida" se associou inequivocamente ao percurso dele e de outros escritores românticos, em uma representação da poesia emanando do íntimo do sujeito melancólico, em arroubos de inspiração, rito legitimador da escrita literária inteiramente diverso daquele que Maingueneau analisa nos escritores naturalistas, com suas pesquisas e notas.

Por sua vez, a face mais claramente histórica dos ritos genéticos de um escritor - aquela apreensível por meios clássicos, como a documentação, o testemunho etc. -, que remete à sua existência e aos percalços documentados de sua escrita, evoca o conceito de biografia, analisado, em $O$ contexto da obra literária, como "bio/grafia": um movimento da vida para a grafia e da grafia para a vida, em um envolvimento recíproco da existência e da escrita. Afinal, a obra já faz parte da existência, seja de maneira mais subjacente, seja na explicitude de narrativas autobiográficas, como Memórias do Cárcere, por exemplo, que começou como projeto de registro na prisão e que, portanto, compôs a própria experiência e parte mesmo da sobrevivência de Graciliano Ramos nos porões da ditadura Vargas.

\section{Análise do Discurso e Texto Literário: um diálogo promissor}

À guisa de conclusão, retomaremos neste ponto o desafio lançado por Maingueneau (2010) já explicitado no início do presente artigo, quando o autor faz menção ao que a Análise do Discurso pode ganhar ao se confrontar com o texto literário. Para além das desconfianças dos "especialismos" que veem uma forte incompatibilidade entre discurso e texto literário, buscaremos aqui desenvolver algumas das ideias que Maingueneau (2010) não faz senão esboçar a respeito.

Comecemos pelas repercussões sobre o quadro teórico da Análise do Discurso de toda a investigação relativa aos ritos genéticos, modos de

\footnotetext{
Cf. biografia na página da Academia Brasileira de Letras dedicada ao autor, disponível em: <http://migre.me/slmMD>.
} 
difusão e de consumo do texto literário. Uma primeira observação a ser feita diz respeito à visibilidade que tais dispositivos ganham como integrantes de uma semântica global. A esse respeito, lembramos que, no terceiro capítulo de Gênese dos discursos, o autor nomeava sete dispositivos para delinear um perfil dessa semântica global (a saber, intertextualidade, vocabulário, temas, estatuto dos coenunciadores, dêixis enunciativa, modo de enunciação e modo de coesão). Se é certo que nunca fez parte do projeto do autor fornecer uma lista exaustiva de dispositivos relevantes para a sua semântica global, é igualmente certo que os ritos genéticos e os modos de difusão e consumo ali não tinham qualquer visibilidade efetiva. É o estudo do texto literário numa abordagem discursiva que vem conferir essa visibilidade aos referidos dispositivos, os quais se mostram igualmente de grande produtividade na análise de outros tipos de textos.

A ideia de que o tipo de produção, circulação e consumo é instituído pelo próprio discurso por intermédio de seu universo semântico remete à constatação de que são vários os aspectos que se encontram no conceito de semântica global, desenvolvido pelo autor. Trata-se, ao contrário do que possa parecer, de uma conjugação de elementos sem etapismo ou forma de sucessão:

... não há inicialmente uma instituição, depois massa documental, enunciadores, ritos genéticos, uma enunciação, uma difusão e, por fim, um consumo, mas uma mesma rede que articula semanticamente essas diversas instâncias. (MAINGUENEAU, 2008, p. 135-136).

Como se percebe, a proposta de Maingueneau diz respeito a um outro modo de pensar a antiga questão da relação entre texto e contexto. Não há preexistência do contexto em relação aos enunciados produzidos, ou seja, enunciados não são produzidos em um espaço e em um tempo preexistentes. Quando se concebe o contexto como meio preexistente aos enunciados, estes são regularmente tomados como representação de algo ocorrido, ou então como sendo motivados por algo que efetivamente acontece no mundo - como se o enunciado não tivesse sua força acontecimental. Tal concepção é uma forma de tornar os textos menos relevantes em termos de produção de mundo, de real. Uma concepção de linguagem que, portanto, 
não nos interessa acolher e que se fragiliza no confronto com os exemplos que buscamos aqui levantar.

Segundo a semântica global, não há primeiro a escolha de um tema, para então se dar a seleção dos vocábulos que lhe sejam adequados, a seguir a escolha de um tipo de concatenação de enunciados, de uma posição para os coenunciadores etc. Uma tal concepção de linguagem - e, em especial, do fenômeno literário - como a que preconiza Maingueneau implica uma requalificação importante: os textos, incluindo-se os literários, não contam o que é o mundo; eles (co)produzem esse mundo. Dizer, enunciar é (também) uma forma de produzir esse mundo - que o diga, de forma bastante aguda, o caso do romantismo alencarino na construção do nacional. Por essa razão a inadequação de uma concepção etapista: enunciados que se produzem, que circulam, que são consumidos de forma tal ou qual, em uma ordenação não apenas temporal, mas também hierarquizante. Ao contrário, enunciados só se produzem com qualidades dessa ou de alguma outra ordem quando estão dadas as condições de circulação e de consumo que legitimarão tal produção, tal posição de enunciador, um dado etos, etc. A tal concepção não representacional de linguagem temos chamado, em Análise do Discurso, de linguagem-intervenção, diferente da linguagem-representação (ROCHA, 2014). Com efeito, não é produtivo conceber que exista, de um lado, o mundo acontecendo e, de outro, esse mesmo mundo sendo falado, narrado ou descrito. Dentre as coisas que acontecem no mundo estão, afinal, os enunciados.

Coerentemente com tal concepção de linguagem embutida no debate acerca dos ritos genéticos e da não hierarquização dos diferentes integrantes de uma semântica global, o conceito de prática discursiva (MAINGUENEAU, 2008, p. 136) vem garantir a indissociabilidade entre os textos e seus ambientes de ocorrência: a produção de textos é acompanhada da produção de um espaço que lhes será compatível (espaço esse que se apreende no tipo de sociabilidade instituída entre os coenunciadores) e, de forma análoga, a produção de uma dada forma de sociabilidade sempre estará ancorada em textos que lhe trarão concretude. Mesmo quando os textos operam no sentido da desconstrução das formas aceitas de sociabilidade, como apontamos em Machado, estão se inscrevendo no curso de um questionamento que integra a experiência de coenunciadores de uma dada época; a crítica à corrente hegemônica, afinal, existe em face dessa mesma hegemonia. 
Ao debater sobre a noção de incorporação (MAINGUENEAU, 2008, p. 96), que diz respeito à construção de um etos de acordo com o qual o modo de enunciação espelha certa compleição física e psicológica do enunciador, Maingueneau aponta três dimensões complementares: o próprio corpo textual confere corporeidade ao enunciador, que passa a funcionar em relação ao destinatário como fonte legitimante de certa maneira de habitar o mundo, sendo assegurada, desse modo, a "incorporação imaginária" desse destinatário à comunidade (não empírica, é certo) daqueles que dão adesão ao discurso. Ora, tal comunidade é apresentada pelo autor, no contexto de suas discussões sobre o texto literário, como "uma comunidade futura, os leitores, convidados a compartilhar seu universo" (MAINGUENEAU, 1995, p. 110). De tal imbricação entre textos e espaços institucionais resulta essa nova concepção de discurso, entendido como entrada que nos oportunizará uma leitura do real que nos cerca, possibilitando-nos investir em certo modo de apreensão do plano social que constituirá uma singularidade do profissional que trabalha com a linguagem.

Inserir no contexto de uma semântica global a reflexão sobre os ritos genéticos possibilita, também, avançar no tipo de tratamento a ser dispensado aos textos, segundo indica Foucault. Com efeito, quando propõe transformar documentos em monumentos ${ }^{10}$ (FOUCAULT, 1972, p. 14), o autor sugere um modo alternativo de lidar com a textualidade: ao invés de trabalhar com o texto-documento, o qual exerce uma função essencialmente referencial, aproximando-se, desse modo, do lugar de ocorrência das palavras "transitivas" (MAINGUENEAU, 2012, p. 16), o autor sugere abrir espaço para o texto-monumento, objeto que, em consonância com a postura genealógica adotada por Foucault, deve ser desmontado, remontado. Assim, a coerência desse texto-monumento seria buscada não numa correspondência com um real que lhe seja exterior, mas em sua possibilidade de fracionamento em unidades menores que autorizem construções infinitas, a exemplo do que se verifica com a multiplicidade de dispositivos integrantes de uma semântica global. Retomando Foucault (1972, p. 14), “o documento não é o

${ }^{10}$ Em artigo publicado em 1968, intitulado "Sur l'archéologie des sciences. Réponse au Cercle d'épistémologie", Foucault declara haver tomado de empréstimo a G. Canguilhem essa concepção de "monumento". 
feliz instrumento de uma história que seria nela mesma, e de pleno direito, memória...". Dito de outro modo, trata-se de recusar o trabalho de mera interpretação dos textos, de desvendamento de algum conteúdo que ali esteja escondido e que, uma vez explicitado, diria a verdade que se dissimulava no texto - perspectiva que não compartilhamos por se mostrar mais compatível com uma análise de conteúdo -, para instituir um modo de apreensão de discursos e saberes como objetos a serem descritos, inter-relacionados, rearticulados, com o objetivo de explicitar suas regras de organização e as condições históricas de possibilidade de emergência de um dado discurso.

Nesse sentido, entendendo que os diferentes dispositivos acionados por uma semântica global ajudam a implementar aquilo que, segundo Maingueneau (2008, p. 52), não foi preocupação de Foucault, a saber, dar consistência a um modo de trabalhar a textualidade, assumimos aqui uma perspectiva divergente da sustentada pelo autor quando se questiona acerca de possíveis "efeitos indesejáveis" da concepção de discurso como monumento:

O desejo de libertar-se de uma história concebida como 'ressurreição integral do passado’ não deve converter a análise do discurso na pura descrição de um imbricamento de pistas, desconsiderando o fato de que essas pistas são as de um discurso, e não as de um templo ou de um retábulo. (MAINGUENEAU, 2008, p. 19).

Não é desse modo que entendemos a questão, em especial quando o que está em debate é o texto literário. Segundo avaliação que fazemos, abordar os textos vistos como monumentos pelo viés da semântica global é uma perspectiva produtiva e que ajuda a promover um caminho metodológico de análise. Mais que isso, trata-se de perspectiva que, pelas múltiplas combinações de dispositivos de análise que autoriza, vem desnaturalizar um conceito bastante caro às abordagens discursivas: a memória, vista não como mero acúmulo de fatos alinhados no tempo, mas como elemento que ressignifica a própria constituição da noção de língua como efeito do texto literário. Se aqui dizemos que um dos efeitos alcançados é a desnaturalização da própria noção de memória, é porque, como lembra Maingueneau, o que em geral se imagina é que, primeiramente, se estabilizam formas de uma 
língua para, em seguida, com base na memória construída, surgirem os textos literários: engodo do senso comum que não deixa ver que o texto literário, longe de representar mero ornamento, atua como forte elemento de coesão entre formas de enunciabilidade e a produção de ritos historicamente circunscritos que participam da constituição de uma comunidade linguística. Como sustenta o autor,

... só passa a haver de fato língua a partir do momento em que a 'massa falante' passa a ser acompanhada por uma comunidade de ausentes, um tesouro de falas mortas. Apoiada num corpus literário, a língua se mantém com base em enunciados de qualidade que de certo modo lhe escapam.(MAINGUENEAU, 2012, p. 197).

\section{Referências}

AGUIAR, D. B. A. Dicções da comunidade imaginada. Cadernos do CNLF, v. 11, n. 7, p. 133-142, 2008.

ASSIS, J. M. M. de. Machado de Assis: obra completa. v. 1. Rio de Janeiro: Nova Aguilar, 1986a.

ASSIS, J. M. M. de. Machado de Assis: obra completa. v. 3. Rio de Janeiro: Nova Aguilar, 1986b.

CANDIDO, A. Literatura e sociedade: estudos de teoria e história literária. 6. ed. São Paulo: Nacional, 1980.

CANDIDO, A. Fiçãa e confissão: ensaios sobre Graciliano Ramos. 13. ed. Rio de Janeiro: Ouro sobre Azul, 2006.

CHARTIER, R. (Org.). Práticas da leitura. Tradução Cristiane Nascimento. 4. ed. São Paulo: Estação Liberdade, 2009.

DEUSDARÁ, B. Discurso e práticas intersemióticas: formas de resistência na contemporaneidade. Soletras, v. 24, p. 300-316, 2012. 
FREITAS, R. D. S. José de Alencar e o Instituto Histórico e Geográfico Brasileiro: apontamentos sobre a concepção do romance 'As Minas de Prata' (1862-1865) e a cultura histórica brasileira nos oitocentos. Aedos, Porto Alegre, v. 2, n. 5, p. 8-25, jul./dez. 2009.

FOUCAULT, M. Arqueologia do Saber. Tradução Luiz Felipe Baeta Neves. Petrópolis: Vozes; Lisboa: Centro do Livro Brasileiro, 1972.

GIVONE, S. O intelectual. In: FURET, F. O bomem romântico. Tradução Miguel Serras Pereira. Lisboa: Presença, 1999.

MAINGUENEAU, D. O contexto da obra literária. Tradução Marina Appenzeller. Rev. trad. Eduardo Brandão. São Paulo: Martins Fontes, 1995.

MAINGUENEAU, D. Gênese dos discursos. Tradução Sírio Possenti. São Paulo: Parábola, 2008.

MAINGUENEAU, D. Análise do discurso e literatura: problemas epistemológicos e institucionais. Tradução Roberto Leiser Baronas; Samuel Ponsoni. Linguasagem, 13. ed., art. 1, maio/jun. 2010. Disponível em: <http://bit.do/bFam6>. Acesso em: 30 jan. 2015.

MAINGUENEAU, D. Discurso literário. 2. ed. Tradução Adail Sobral. São Paulo: Contexto, 2012.

MOISES, M. Dicionário de termos literários. 12. ed. rev. e ampl. São Paulo: Cultrix, 2004.

PEREIRA, C. A. M. Retrato de época: poesia marginal anos 70. Rio de Janeiro: Funarte, 1981.

ROCHA, D. Representar e intervir: linguagem, prática discursiva e performatividade. Linguagem em (Dis)curso, Tubarão, v. 14, n. 3, p. 619-632, set./dez. 2014.

Recebido em: 16/03/2015 Aceito: $17 / 08 / 2015$ 